\title{
Effect of temperature and viscosity on swimming velocity of the copepod Acartia tonsa, brine shrimp Artemia salina and rotifer Brachionus plicatilis
}

\author{
Poul S. Larsen ${ }^{1, *}$, Caroline V. Madsen ${ }^{2}$, Hans Ulrik Riisgård ${ }^{2}$ \\ ${ }^{1}$ Department of Mechanical Engineering, Fluid Mechanics Section, Technical University of Denmark, Building 403, \\ 2800 Kgs. Lyngby, Denmark \\ ${ }^{2}$ Marine Biological Research Centre, University of Southern Denmark, Hindsholmvej 11, 5300 Kerteminde, Denmark
}

\begin{abstract}
Beating cilia are important organelles for swimming in many zooplanktonic aquatic organisms, including many invertebrate larvae, rotifers and ciliates, but other planktonic organisms, such as copepods and brine shrimps, use muscle-powered swimming appendages. In recent studies we found that the temperature-dependent viscosity of seawater is the key physical/mechanical factor that controls the beat frequency of water-pumping cilia in mussels and the swimming velocity in a ciliate. The present study on the swimming velocity of 3 zooplankton organisms, however, shows that the response of swimming velocity to a change in viscosity is different when due to a change in temperature or, at constant temperature, due to a manipulation of viscosity by addition of a high-molecular-weight polymer (polyvinyl pyrrolidone, PVP) to the ambient seawater. There is a biological effect (fraction of total reduction of swimming velocity for a $10^{\circ} \mathrm{C}$ temperature reduction) that is found to be largest for the brine shrimp Artemia salina nauplius (37\%) and the rotifer Brachionus plicatilis $(26 \%)$, but negligible for the copepod Acartia tonsa (4\%). We suggest that experimental data on change in swimming velocity $(V)$ due to change in kinematic viscosity $(v)$ be correlated in terms of a power law, $V \propto v^{-m}$. The present data on swimming velocity of copepods, brine shrimps and rotifers show values of exponent $m \approx 1.5$ to 3 , with a trend of decreasing values for increasing size of species. Differences in $m$-values may be ascribed to differences in propulsion system, body drag and size.
\end{abstract}

KEY WORDS: Swimming velocity $\cdot$ Temperature $\cdot$ Kinematic viscosity $\cdot$ PVP $\cdot Q_{10}$ Resale or republication not permitted without written consent of the publisher

\section{INTRODUCTION}

A recent study indicates that the effect of temperature on water-pumping lateral cilia in the gill of the blue mussel Mytilus edulis may be purely mechanical, controlled by the viscosity of the ambient seawater (Riisgård \& Larsen 2007). A consequence of viscosity having a pronounced effect on ciliary beat frequency is that temperature-dependent viscosity is likely to exert a strong effect on the swimming speed of aquatic organisms that use cilia for propulsion. This statement is in agreement with Podolsky \& Emlet (1993) who found that the swimming velocity of larvae of the sand dollar Dendraster excentricus was reduced by about
$40 \%$ when the temperature was reduced from 22 to $12^{\circ} \mathrm{C}$, and about $40 \%$ of this decrease could be ascribed to the increase in viscosity. Similar results were obtained by Bolton \& Havenhand (1997) who studied the viscosity-induced effects of water temperature on the swimming velocity of larvae of the polychaete Galeolaria caespitosa. On average, about half the decline in swimming velocity was found to be caused by mechanical effects of increased viscosity while the remainder was presumed to be due to physiological effects. Evidently, the viscosity of water is a key factor for ciliary swimming velocity of aquatic zooplankton organisms. But the effect of temperaturedependent viscosity for the swimming velocity of crus- 
tacean zooplankton organisms that use musclepowered swimming feet and other appendages for propulsion is unknown, although it is of considerable importance for a basic understanding of the effect of temperature in the aquatic environment (Loiterton et al. 2004).

The aim of the present study was to analyze the effect of temperature-dependent viscosity of the ambient seawater on the swimming velocity of different suspension-feeding zooplankton organisms using either cilia (rotifers) or muscle-powered swimming appendages (copepods and brine shrimps) for swimming. This was done by using video-microscope recordings of zooplankton organisms at different temperatures of seawater and at different viscosities at constant temperature, obtained by adding polyvinyl pyrrolidone (PVP) to manipulate the viscosity of seawater. It was presumed that measured velocities in the first case would show the response to both biological and physical changes, while the second case would show only the response to physical changes, under the premise that there is no separate biochemical effect of dilute solutions of PVP on organisms.

\section{MATERIALS AND METHODS}

Experimental animals. The effect of temperature and PVP-manipulated viscosity were studied on 3 marine suspension-feeding zooplankton organisms.

Copepods: The calanoid copepod Acartia tonsa has adopted 2 fundamentally different prey encounter strategies, suspension feeding and raptorial (or ambush) feeding (Jonsson \& Tiselius 1990, Kiørboe et al. 1996). In the suspension-feeding mode, the copepod swims freely in small 'bursts', often designated 'feeding bouts', during which it generates a feeding current (by movement of the second antennae, first maxillae and maxillipeds) to encounter and capture immobile prey (i.e. swimming and feeding are combined as in most other copepod species). In the raptorial feeding mode, the copepod sinks slowly, perceiving motile prey by means of mechanoreceptors on the antennae. In the present study, video observations were made of free-swimming A. tonsa (length $1095 \pm 23 \mu \mathrm{m}$, width $1490 \pm 85 \mu \mathrm{m}$ [antennae], $200 \mu \mathrm{m}$ [prosome]; all adults obtained from a laboratory culture supplied by Danish Fisheries Research), that were stimulated to suspension-feed by adding about 3000 Rhodomonas sp. cells $\mathrm{ml}^{-1}$ to the observation chamber.

Brine shrimps: Brine shrimp Artemia salina, $3 \mathrm{~d}$ old nauplii with only 3 pairs of swimming appendages, from commercially produced eggs from a local dealer, length $697 \pm 60 \mu \mathrm{m}$, width $758 \pm 10 \mu \mathrm{m}$, cultivated in glass flasks $\left(22^{\circ} \mathrm{C}, 20 \mathrm{psu}\right)$ on a diet of flagellates (Rho- domonas sp.) were used for measurement of swimming velocity.

Rotifers: Brachionus plicatilis is a pelagic rotifer that swims continuously, and propulsion for swimming is provided by the beating cilia of the extended 'wheel organ' or corona. Here, the prototroch and metatroch consisting of compound cilia form a downstreamcollecting system. The prototroch is larger than the metatroch and the main water current is thus towards the posterior pole of the animal, and consequently, the swimming direction is anterior (Strathmann et al. 1972, Nielsen 1987, 1995). B. plicatilis (length $228 \pm 74 \mu \mathrm{m}$, width $125 \pm 30 \mu \mathrm{m}$ ) obtained from a culture supplied by Danish Fisheries Research and used for measurement of swimming velocity were cultivated in glass flasks $\left(22^{\circ} \mathrm{C}, 20 \mathrm{psu}\right)$ on a diet of flagellates (Rhodomonas sp.).

Swimming velocities. A number of zooplankton organisms were transferred to a temperature-controlled observation chamber (width $\times$ depth $\times$ height $=8.5 \times$ $3.5 \times 7 \mathrm{~cm}$ ). The motility of the animals was studied by means of a stereo microscope (Leica MZ8) equipped with a video camera (Leica ICA) recording 50 frames $\mathrm{s}^{-1}$. A dark background and a laser sheet (Global Laser) with a width of about $1 \mathrm{~mm}$ ensured that all recorded swimming tracks, typically lasting at least 50 frames, were parallel to the optical plane. A criterion for accepting a swimming track was that the intensity of reflected red laser light from a swimming organism should be strong and constant during the entire observation period (transverse, out-of-plane swimming was revealed by a varying intensity of reflected light). Due to the large number of animals in the chamber it is unlikely that the same animal was recorded more than once. Movements were traced from their positions in successive video frames. Swimming velocities were recorded at different temperatures and in PVPmanipulated seawater at constant temperature, by plotting the positions of a zooplankton organism frame by frame on a transparent overlay on the video monitor screen.

Manipulation of viscosity. The kinematic viscosity $\left(v, 10^{-6} \mathrm{~m}^{2} \mathrm{~s}^{-1}\right)$ of seawater as a function of temperature $\left(T,{ }^{\circ} \mathrm{C}\right)$ has been measured and expressed as: $v=$ $0.0005 \exp [2260 /(T+273.15)]$, and the inverse function $T e=2260 / \ln (2000 v)-273.15$ was used for estimating the temperature equivalent ( $T e$ ) for actually measured viscosity of manipulated seawater samples at the selected reference temperature $\left(20^{\circ} \mathrm{C}\right)$. Kinematic viscosity was measured using a calibrated viscometer (Ubbelohde Viscometer fitted with a tempering jacket; Schott).

The desired viscosity of manipulated seawater samples used in the observation chamber was obtained by adding PVP (PVP360 = Polyvidone = PVP, average 
molecular weight 360000 ; Sigma-Aldrich) to $20 \mathrm{psu}$ strongly stirred seawater. A main solution of PVP (10.5 g PVP dissolved in $100 \mathrm{ml} 20$ psu seawater) was prepared at least $1 \mathrm{~d}$ before use, and different lower viscosities were obtained by diluting with seawater.

Experimental design. In search of laws governing the dependence of viscosity, we designed the experiments to cover a range of temperatures and viscosity values that could disclose a functional relationship. The acute (hours) effect of temperature was measured on 5 individuals in a relatively dense population of each of the 3 zooplankton species transferred to the temperature-controlled observation chamber $1 \mathrm{~d}$ before the measurements. Individuals were at least 20 body lengths apart, which excluded unintended interactions. The water temperature was first increased in a stepwise manner from the acclimation temperature (1 d) of 10 or $15^{\circ} \mathrm{C}$ to about $20^{\circ} \mathrm{C}$ with intervals of about $5^{\circ} \mathrm{C}$. At each temperature step, the swimming velocity was measured on 5 randomly chosen individuals on the video tape, and subsequently, the temperature was stepwise reduced and the swimming velocity measured at $5^{\circ} \mathrm{C}$ intervals before the temperature was finally adjusted to the original acclimation temperature. This was done to ensure that the acute temperature effects were reversible. Then subsequently, adjusting the temperature to the reference state of $20^{\circ} \mathrm{C}$, the viscosity was stepwise increased by adding PVP to the observation chamber and it was measured on a sample withdrawn from the chamber. Fifteen to 30 min after the addition of PVP, swimming velocities were measured at each different Te-value, down to about $\mathrm{Te}=6^{\circ} \mathrm{C}$.

Power law. Based on previous findings that the beat frequency of lateral cilia in the mussel Mytilus edulis depends on viscosity in a manner well-correlated by a power law, $f \approx v^{-m}, m \approx 1.5$ (Riisgård \& Larsen 2007), we anticipate that the appendages and cilia responsible for propulsion of the present zooplankton organisms, and hence their swimming velocities, would respond to changes in viscosity in a similar manner, but not necessarily with the same value of the exponent. This power law, which is applied in the present study, may be summarized as follows. For the swimming velocity $V$ of an organism of diameter $D$ through water of kinematic viscosity $v$ by the propulsive action of appendages (or cilia) of length $\ell$ and beat frequency $f$, we can form 3 dimensionless groups, e.g. $\Pi_{1}=V /(\ell f)$, $\Pi_{2}=\ell / D$ and $\Pi_{3}=V D / v$. Hence we expect a relationship of form $\Pi_{1}=a \Pi_{2}{ }^{b} \Pi_{3}{ }^{c}$, where $a, b$ and $c$ would be constants for a given range of parameters. This approach of dimensional analysis (see e.g. White 2003, their Chapter 5) is often used in theoretical analyses and for the correlation of data in mechanics and fluid mechanics. For a given species of constant $D$ and $\ell$, and for $f \propto v^{-m}$, this leads to the relationship $V \propto v^{-n}$, where $n=(m+c) /(1-c)$ is a new constant. The case of $C=0$ corresponds to no effect of the Reynolds number $\Pi_{3}$, leading to $n=m$, and we recover $V \propto v^{-m}$. However, increasing positive values of $c<1$, implying a Reynolds-number effect, would lead to increasing values of the exponent $n$. When no theory is available, $n$ must be determined from experiments. Furthermore, given 2 observations (1 and 2 ) of swimming velocity and corresponding kinematic viscosity, the power law implies the relationships:

$$
V_{2} / V_{1}=\left(v_{2} / v_{1}\right)^{-n} \text { and } n=-\ln \left(V_{2} / V_{1}\right) / \ln \left(v_{2} / v_{1}\right)
$$

These relationships may be used to estimate the value of the exponent $n$ from '2-point experiments', which are typical of most previous investigations that have considered only 2 temperatures/viscosities, say separated by $10^{\circ} \mathrm{C}$.

Biological effect. Within the temperature interval tolerated by poikilotherms, the metabolic rate (respiration rate) increases with increasing temperature. Often the metabolic rate approximately doubles for a temperature rise of $10^{\circ} \mathrm{C}$. The ratio of rates measured $10^{\circ} \mathrm{C}$ apart is called $Q_{10}$ and mathematically described by an exponential function (Schmidt-Nielsen 1970):

$$
Q_{10}=\left(R_{2} / R_{1}\right)^{10 /(T 2-T 1)}
$$

or the inverse,

$$
R_{2} / R_{1}=Q_{10}^{(T 2-T 1) / 10}=\exp \left[\left(T_{2}-T_{1}\right)\left(\ln Q_{10}\right) / 10\right]
$$

where $R_{2}$ and $R_{1}$ are the metabolic rates at 2 temperatures, $T_{2}$ and $T_{1}$. Many biochemical and enzymatic reactions are dependent on temperature and accelerated in a similar way, i.e. they have a $Q_{10}$ of about 2 to 3 . Because it was to be expected that the swimming velocity of the zooplankton organisms studied in the present work would increase with increasing temperature, an important question to be answered was whether part of the increase in swimming velocity could be due to increased biological activity. Thus, if the rate of change in swimming velocity is closely coupled to metabolism, increases in swimming velocity $(V)$ with increasing temperature should be exponential; therefore, the present data for $V(T)$ have been approximated by exponential regression lines that enable us to make an evaluation of $Q_{10}$ for a possible separate biological effect, apart from the physical/mechanical temperature-dependent effect of viscosity.

Data analysis was performed on the basis of the following considerations. Suppose the exponential regression lines for experiments $V(T e)$ with changing viscosity at constant temperature $\left(T_{0}\right)$ and for experiments $V(T)$ with changing temperature, respectively, are of the form: 


$$
V(T e)=a_{1} \exp \left(b_{1} T e\right) \text { and } V(T)=a_{2} \exp \left(b_{2} T\right)
$$

If, further, the data of the 2 experiments coincide (as they should) at the reference state of pure seawater at $V_{0}$ and $T_{0}$, Eq. (4) may be written as

$$
\begin{aligned}
& V(T e)=V_{0} \exp \left[b_{1}\left(T e-T_{0}\right)\right] \text { and } \\
& V(T)=V_{0} \exp \left[b_{2}\left(T-T_{0}\right)\right]
\end{aligned}
$$

since then, $V_{0}=a_{1} \exp \left(b_{1} T_{0}\right)=a_{2} \exp \left(b_{2} T_{0}\right)$. Setting $R_{1}=V(T e), R_{2}=V(T), T_{1}=T_{0}$, and $T_{2}=T=T e$, insertion of Eq. (5) into Eq. (2) gives

$$
Q_{10}=\exp \left[10\left(b_{2}-b_{1}\right)\right]
$$

which is used to estimate the separate biological effect. A value of $Q_{10}=1$ corresponds to no biological effect.

Some authors give both the percentage reduction of swimming velocity for a viscosity increase due to additives (at constant temperature) corresponding to a temperature reduction of $10^{\circ} \mathrm{C}$, and the percentage reduction of swimming velocity for the same temperature reduction of $10^{\circ} \mathrm{C}$ without additives. Using Eq. (5) we may express these 2 reductions ( $\phi_{\text {visc }}$ representing the physical/mechanical effect of increased viscosity alone, and $\phi_{\text {total }}$ the combined physical/mechanical and biological effects, respectively) as:

$$
\begin{aligned}
& \varphi_{\text {visc }}=\left[1-\exp \left(-10 b_{1}\right)\right] \times 100 \text { and } \\
& \varphi_{\text {total }}=\left[1-\exp \left(-10 b_{2}\right)\right] \times 100
\end{aligned}
$$

Further, the percentage of total reduction due to biological effects (often given as well) may then be evaluated as

$$
\varphi_{\text {bio }}=\left[\left(\varphi_{\text {total }}-\varphi_{\text {visc }}\right) / \varphi_{\text {total }}\right] \times 100
$$

It may be argued that while a purely biological effect according to the $Q_{10}$ theory should correlate with the exponential relation in Eq. (4), such a relationship might not be valid if part or all of the observed response due to a temperature change were caused by physical/mechanical effects of, say, changing viscosity. However, this may still be approximately true as long as the viscosity dependence of swimming velocity can be expressed by the power law and as long as the temperature dependence of viscosity can be expressed by an exponential function as indicated in the section 'Manipulation of viscosity'. This is readily shown by simply substituting this expression for viscosity into the power law and using the approximation $1 /(1+x) \approx 1-x$ for $x \ll 1$, noting that $T e \ll$ $273.15^{\circ} \mathrm{C}$.

\section{RESULTS AND DISCUSSION}

The experimentally determined values of swimming velocity $(V)$ as a function of temperature ( $T$-data) and temperature equivalent (PVP- or Te-data), as well as a function of kinematic viscosity $(v)$, are shown in Figs. 1, 2 \& 3. In Figs. 1A, 2A \& 3A, exponential regression lines $\left(V(T e)=a_{1} \exp \left(b_{1} T e\right)\right.$ and $\left.V(T)=a_{2} \exp \left(b_{2} T\right)\right)$ appear to represent trends well, and their coefficients $b$ are listed in Table 1. In Figs. 1B, 2B \& 3B, on the other hand, power-law regression lines $\left(V \propto v^{-m}\right)$ reflect systematic trends reasonably well and their exponents $m$ are given in Table 1. Here, despite the scatter of data, we see that coefficient $b_{1}$ for Te-data are always smaller than coefficient $b_{2}$ for T-data. Using Eq. (6) and Table 1, the separate biological effect is small or negligible for Acartia tonsa $\left(Q_{10}=1.03\right)$, but significant for Artemia salina and Brachionus plicatilis $\left(Q_{10}=1.38\right.$ and 1.35, respectively). Using Eq. (8) and Table 1, the biological effect in relation to the total reduction in swimming velocity amounts to only $4.1 \%$ for $A$. tonsa, but as much as $37.1 \%$ and $26.4 \%$, respectively, for A. salina and B. plicatilis. Also, there is a trend of power-law exponents $m$ to be smaller for PVP-data than for T-data for A. salina (Fig. 2B) and B. plicatilis (Fig. 3B), but not for Acartia tonsa (Fig. 1B) where coefficients are nearly the same within the experimental uncertainty, apparently in agreement with the absence of a separate biological effect.

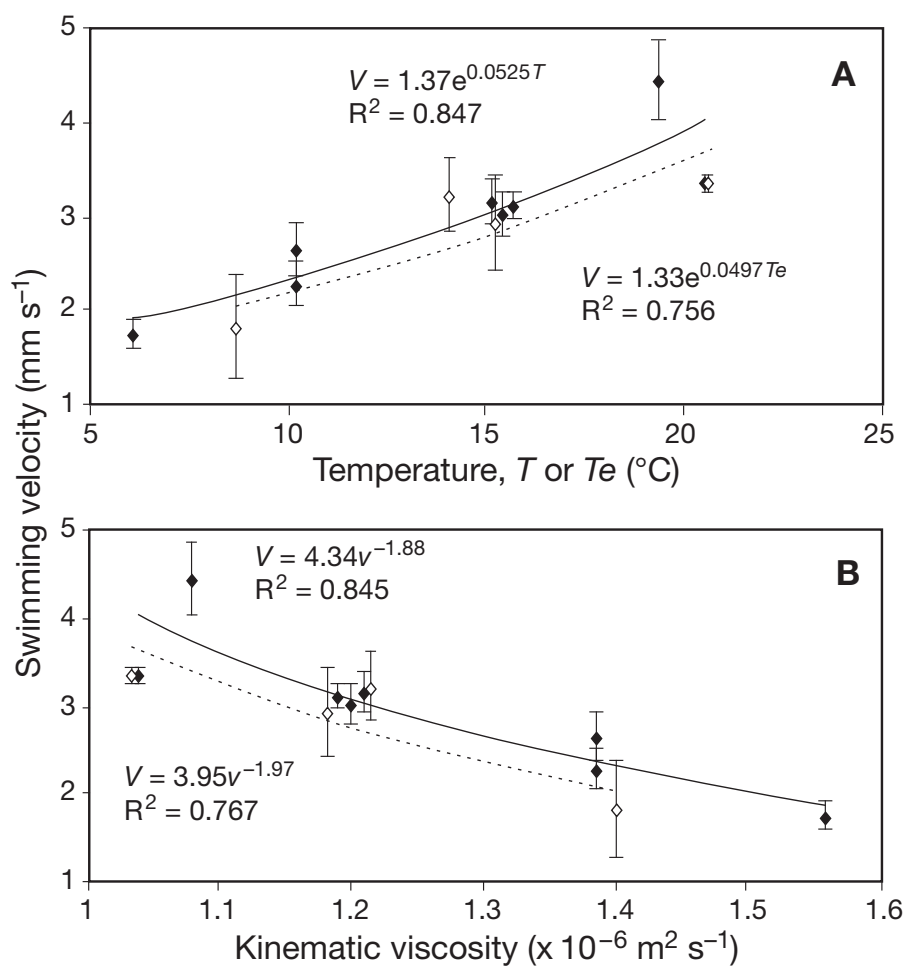

Fig. 1. Acartia tonsa. Effect on swimming velocity $(V)$ of $(\mathrm{A})$ temperature $\left(T\right.$, solid symbols) or PVP at constant temperature $\left(20^{\circ} \mathrm{C}\right)$ ( $T e$, open symbols) and (B) temperature-dependent viscosity (solid symbols) or PVP-induced viscosity at constant temperature $\left(20^{\circ} \mathrm{C}\right)$ (open symbols). Data are mean $\pm \mathrm{SD}(\mathrm{n}=5)$ 


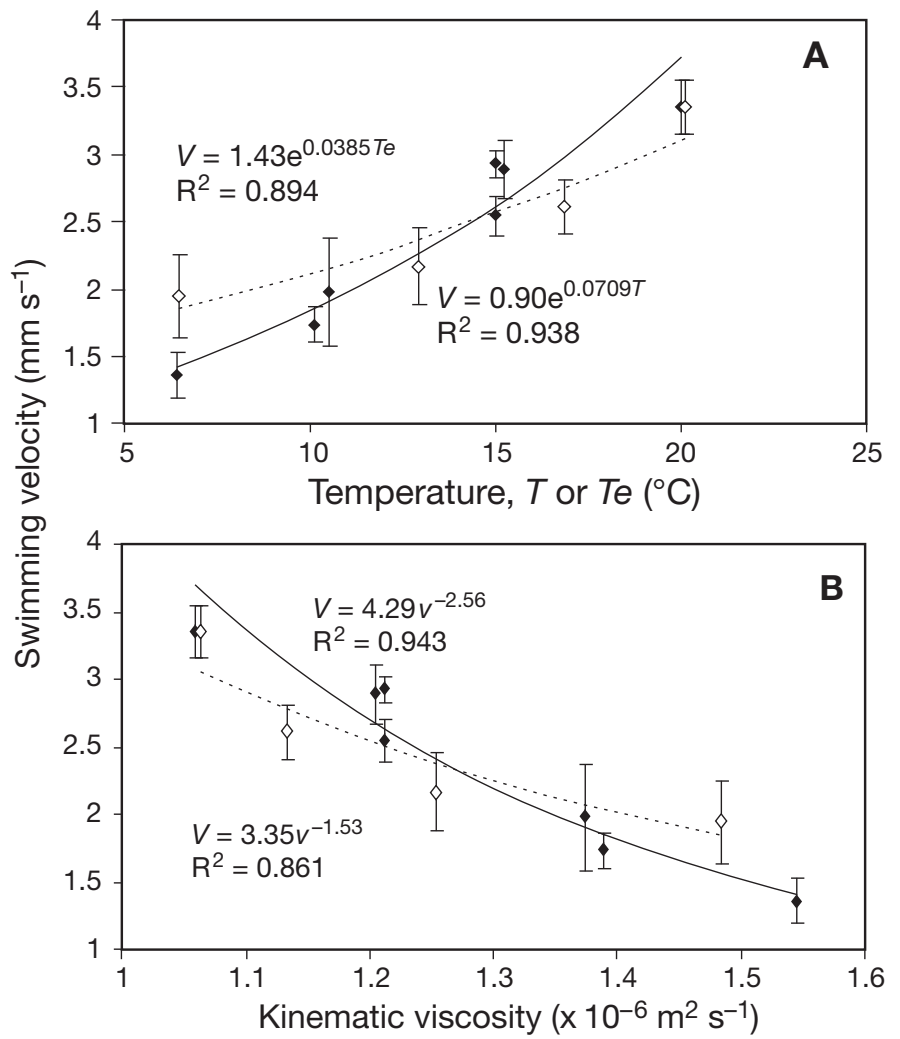

Fig. 2. Artemia salina. Effect on swimming velocity ( $V$ ) of (A) temperature ( $T$, solid symbols) or PVP at constant temperature $\left(20^{\circ} \mathrm{C}\right)(\mathrm{Te}$, open symbols) and $(\mathrm{B})$ temperature-dependent viscosity (solid symbols) or PVP-induced viscosity at constant temperature $\left(20^{\circ} \mathrm{C}\right)$ (open symbols). Data are mean $\pm \mathrm{SD}(\mathrm{n}=5)$

Due to its excess weight (negative net buoyancy), a copepod sinks when in passive mode prior to a freeswimming 'feeding bout' studied here. Tiselius \& Jonsson (1990) observed sinking velocities in the range 0.58 to $0.8 \mathrm{~mm} \mathrm{~s}^{-1}$ depending on orientation of Acartia tonsa. This magnitude of sinking velocity agrees with our estimates of terminal velocity based on a sphere of the same volume as that of the body of $A$. tonsa, but with increased drag due to appendages, and for an excess density of $30 \mathrm{~kg} \mathrm{~m}^{-3}$ (Tiselius \& Jonsson 1990). Since extensive studies of capture efficiency of copepods (see e.g. review by Jiang \& Osborn 2004) show an

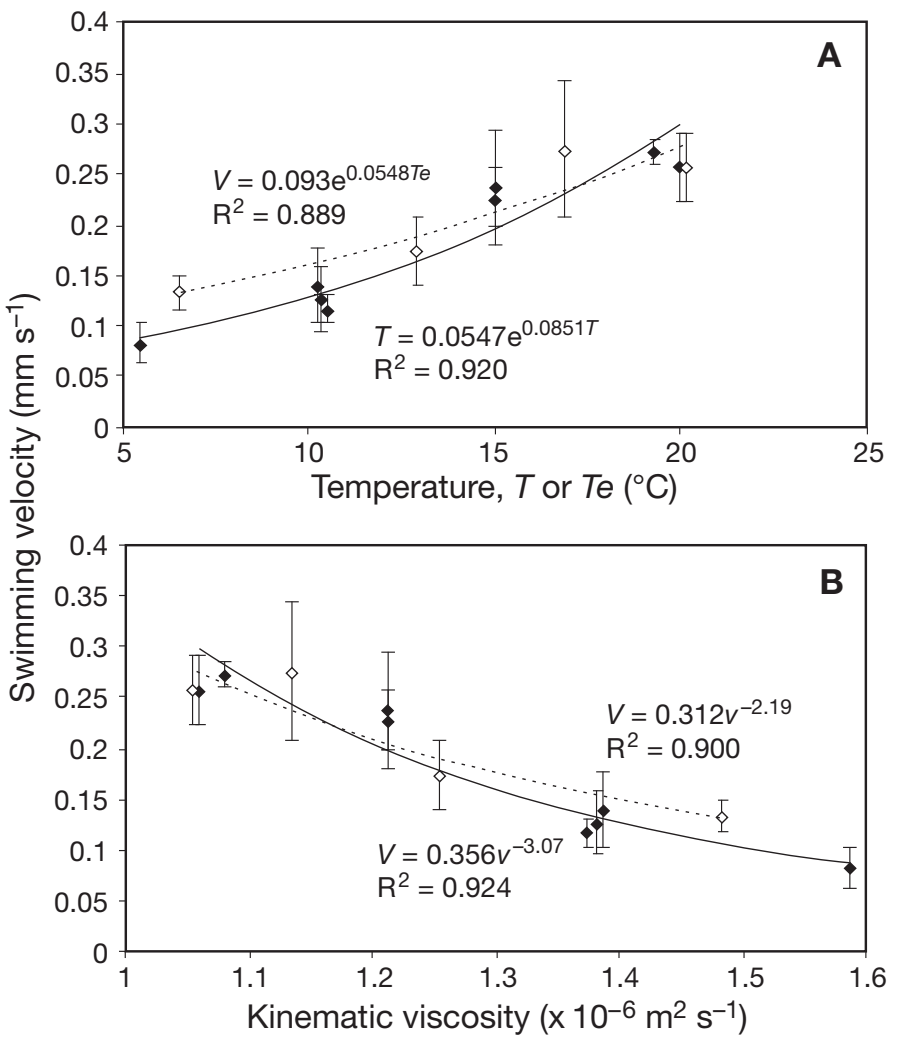

Fig. 3. Brachionus plicatilis. Effect on swimming velocity ( $V$ ) of (A) temperature ( $T$, solid symbols) or PVP at constant temperature $\left(20^{\circ} \mathrm{C}\right)(\mathrm{Te}$, open symbols) and (B) temperature-dependent viscosity (solid symbols) or PVP-induced viscosity at constant temperature $\left(20^{\circ} \mathrm{C}\right)$ (open symbols). Data are mean $\pm \mathrm{SD}(\mathrm{n}=4)$

effect of sinking velocity via track orientation, it may be imagined that the excess density would also affect the measured swimming velocity, all depending on orientation of tracks relative to the vertical. Such effects should show up as increased data scatter since recorded tracks were randomly oriented between horizontal and vertical up. If this were so at the high temperature $\left(20^{\circ} \mathrm{C}\right.$ in Fig. 1A), such scatter should diminish toward the low temperature $\left(5^{\circ} \mathrm{C}\right.$ in Fig. $\left.1 \mathrm{~A}\right)$ by a factor of 1.15 and 1.54, respectively, due to the increase of water density (by a factor of 1.0045) and viscosity, respectively, sinking velocity being proportional to

Table 1. Experimentally determined coefficients $b_{1}$ and $b_{2}\left(\mathrm{R}^{2}\right)$ from exponential regression, $V=a_{1} \exp \left(b_{1} T e\right)$ and $V=a_{2} \exp \left(b_{2} T\right)$ and exponent $m\left(\mathrm{R}^{2}\right)$ from power-law regression, $V \propto \mathrm{v}^{-m}$, of data for swimming velocity $(V)$ versus temperature $(T)$, temperature equivalent (Te) and kinematic viscosity (v), respectively. Unit of $b$ is ${ }^{\circ} \mathrm{C}^{-1}$

\begin{tabular}{|llccccrr|}
\hline Organism & Species & $\begin{array}{c}\text { Length } \\
(\mu \mathrm{m})\end{array}$ & $\begin{array}{c}\text { Width } \\
(\mu \mathrm{m})\end{array}$ & $\begin{array}{c}b_{1}\left(\mathrm{R}^{2}\right) \\
\text { for } T e\end{array}$ & $\begin{array}{c}b_{2}\left(\mathrm{R}^{2}\right) \\
\text { for } T\end{array}$ & $\begin{array}{c}m\left(\mathrm{R}^{2}\right) \\
\text { for PVP }\end{array}$ & $\begin{array}{c}m\left(\mathrm{R}^{2}\right) \\
\text { for } T\end{array}$ \\
\hline Copepod & Acartia tonsa & 1095 & 1490 & $0.0497(0.76)$ & $0.0525(0.85)$ & $1.97(0.77)$ & $1.88(0.84)$ \\
Brine shrimp & Artemia salina & 697 & 758 & $0.0385(0.90)$ & $0.0709(0.94)$ & $1.53(0.86)$ & $2.56(0.94)$ \\
Rotifer & Brachionus plicatilis & 228 & 125 & $0.0548(0.89)$ & $0.0851(0.92)$ & $2.19(0.90)$ & $3.07(0.92)$ \\
\hline
\end{tabular}


$\left(\rho_{\mathrm{c}} / \rho-1\right) / v$, where $\rho_{\mathrm{c}}$ denotes the assumed constant density of the copepod. From inspection of Fig. 1 any such contribution to scatter is overshadowed by other sources, notably functional differences between specimens and experimental uncertainty.

It may be argued that the reference state (pure seawater at $T_{0}$ and $V_{0}$ ) does not exactly coincide for $T e$ data and $T$-data in Figs. $1 \mathrm{~A}, 2 \mathrm{~A} \& 3 \mathrm{~A}$, so that the $Q_{10}$ values calculated from Eq. (6) could be questionable. The lack of coincidence of reference states reflects the experimental uncertainty, but the $b$-coefficients in the exponential regressions represent the average trend of many data points, and hence are significant indicators, and those alone determine the $Q_{10}$ values. It may be shown that a slight adjustment (within the data scatter) of $T_{0}$ and $V_{0}$ used in Eq. (5) gives exponential regressions with the same $b$-coefficients that fit the data essentially as well as those shown in Figs. 1A, 2A \& 3A.

Use of exponential regression to correlate $V(T)$-data in Figs. 1A, 2A \& 3A is logical when seeking a possible biological effect because of the definition of $Q_{10}$ in Eq. (3). Further, in view of the development leading to Eq. (6) for a separate biological effect, it is desirable to also use exponential regression for $V(T e)$-data in the same figures. Until a reliable mathematical model has become available for the combined physical and biological effects on swimming velocity, we really do not know the nature of the functional relation $V\{T, v\}$. Empirical sample calculations, however, have shown that when $V(v)$-data that fit a power-law relation $\left(V(v) \propto v^{-m}\right)$ are transformed into $V(T)$-data by use of the viscosity-relation $v(T)$, these $V(T)$-data fit an exponential regression quite well, but not a linear one.

It is noted that exponents $m$ (range 1.53 to 3.07 from Table 1) are generally larger than the value of $m \approx 1.5$ found for water-pumping cilia in mussels (Riisgård \& Larsen 2007). This is also true for Brachionus plicatilis that uses cilia for propulsion. Table 1 also shows that both coefficient $b$ and exponent $m$ generally increase with decreasing size of animal. The different values of the exponent $m$ probably reflect fundamental differences between species and their propulsion mechanisms and drag (resistance) to motion. For the present experiments, the range of Reynolds numbers $(\mathrm{Re}=$ $V L / V$, based on swimming velocity and length of organisms) are: 1.37 to 3.93 for Acartia tonsa, 0.66 to 1.88 for Artemia salina and 0.014 to 0.061 for B. plicatilis, which indicates a systematic trend related to size. At the lowest values of Reynolds number $(\operatorname{Re} \ll$ 1 ), the drag force on an organism in steady creeping motion should be linear in viscosity and velocity, $F_{\mathrm{d}} \propto v$ $V$, so if the propulsive force were constant we would expect the relationship $V \propto v^{-1}$, which however does not agree with $m$-values for $B$. plicatilis. One reason may be that propulsive force is not constant but decreases with increasing values of viscosity; another may be that drag is more complicated than assumed. As shown by model experiments and model calculations by Lagergren et al. (2000) for 2 species of the cladoceran water flea Bosmina sp., propulsive nonsteady phenomena associated with swimming should be taken into account to evaluate drag force, which is then not linear in velocity.

Most investigations in the past have presented results in terms of percentage reduction in swimming velocity for a given decrease in temperature or equivalent increase in viscosity at constant temperature. Bolton \& Havenhand (1997, their Table 2), for example, found a $31 \%$ reduction in swimming velocity of small (posthatched) larvae of the serpulid polychaete Galeolaria caespitosa in response to a $20.6 \%$ increase in viscosity by inert polymer (Ficoll) addition at $25^{\circ} \mathrm{C}$. However, the decrease in swimming velocity was $60.4 \%$ in response to a lowering of the temperature of seawater from 25 to $15^{\circ} \mathrm{C}$, which gave the same $20.6 \%$ increase in viscosity. The difference between the 2 reductions $(60.4-31=$ $29.4 \%$ ) was interpreted as the separate physiological effect, and assuming swimming velocity to be proportional to metabolic rate, its constant is estimated to be $Q_{10}=1.41$. To interpret these results in terms of a power-law relation, we use Eq. (1) to estimate the exponent as $n=-\ln 0.69 / \ln 1.206=1.98$. However, for their largest specimens, Bolton \& Havenhand (1997) found only a $17.3 \%$ reduction for the same increase in viscosity, leading to the exponent $n=-\ln 0.827 / \ln 1.206=$ 1.01. The decrease in $n$-values with increasing size follows the trend of the present study, although, according to Bolton \& Havenhand (1997), it could not be explained by a Reynolds number dependence but could be related to a size effect of the propulsion system, a conjecture that remains unresolved.

Other similar studies of swimming or feeding performance in response to change in temperature or viscosity have shown the separate contribution from viscosity to account for from about half to all of the observed change in performance (e.g. Podolsky \& Emlet 1993, Podolsky 1994, Fuiman \& Batty 1997, Bolton \& Havenhand 1997, 1998, Hunt von Herbing \& Keating 2003, Loiterton et al. 2004). It therefore appears that the response of performance to changes in viscosity varies among species, their size and the performance in question.

In a study of sand dollar larvae, Podolsky \& Emlet (1993, their Fig. 2) found mean swimming velocities of $0.439,0.369$ and $0.266 \mathrm{~mm} \mathrm{~s}^{-1}$ at T22, T22/ $\mu 12$ and T12, respectively, where T22/ $\mu 12$ signifies a temperature of $22^{\circ} \mathrm{C}$ with PVP addition to increase the kinematic viscosity by $30.8 \%$ to correspond to that of $12^{\circ} \mathrm{C}$ seawater, which translates to $m=-\ln (0.369 / 0.439) / \ln 1.308=$ 0.65 . Their results also showed that about $40 \%$ of the 
total reduction of velocity for a temperature change from 22 to $12^{\circ} \mathrm{C}$ was due to increased viscosity while the remaining $60 \%$ was due 'to other effects of temperature'. Experiments that separate physical and physiological effects of temperature have also been made on fish larvae. Fuiman \& Batty (1997) separated the effects by increasing water viscosity through the addition of methyl cellulose to seawater. Considering small larvae (9.6 mm length), which showed essentially no separate effect of temperature, all data (Fuiman \& Batty 1997, their Fig. 2) proved to be well-correlated by a power law with $m=2.18$. Large larvae (18.2 mm length), on the other hand, responded to both viscosity and temperature, probably because viscosity plays a small role at the higher Reynolds numbers. More recently, Hunt von Herbing \& Keating (2003) studied the effects of temperature-induced changes in the viscosity of water on the swimming velocity of small haddock larvae. For the smallest larvae ( $\sim \mathrm{mm}$ long) swimming velocities

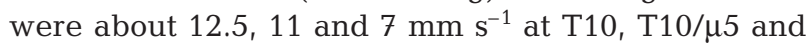
$\mathrm{T} 10 / \mu 0$, respectively (Hunt von Herbing \& Keating 2003, their Fig. 3a), corresponding to kinematic viscosity values of $1.32,1.55$ and $1.82 \times 10^{-6} \mathrm{~m}^{2} \mathrm{~s}^{-1}$ for seawater and 2 concentrations of added methyl cellulose, respectively. The 2 changes in swimming velocity would correspond to $m=0.89$ and 1.98, respectively, but for larger larvae viscosity was not a significant factor. It should be noted that the viscosity of solutions of methyl cellulose are non-Newtonian (see discussion by Bolton \& Havenhand 1998), but it is not possible to estimate how significant this effect would be.

Zooplankton organisms exhibit a wide range of swimming velocities, both in a predator-free environment and in the presence of a predator. Zooplankton prey such as copepods have evolved an adaptive 'escape response' to predatory threat by fish larvae (Beck \& Turingan 2007), and e.g. the 'jumping' ciliate Mesodinium rubrum remains motionless until encountered by a copepod or another predator that generates a hydromechanical signal that provokes an escape jump away from the predator (Jakobsen et al. 2006). However, different zooplankton organisms' ability to accelerate their swimming velocity in response to a predator-or a temperature increase-depends on the organisms' ability to increase the swim-power of the beating cilia (e.g. rotifers and ciliates) or the muscular swimming appendages in e.g. copepods and brine shrimps. Beck \& Turingan (2007) found that all zooplankton prey, except ciliary swimming rotifers and ciliates, significantly increased their swimming velocity in the presence of predatory fish larvae. This observation seems to demonstrate a fundamental difference between ciliary and muscle-powered swimming, because supplementary energy may be allocated to muscular swim-work in response to a predator (or to increased temperature) whereas ciliary organisms do not seem to be able to adjust (or acclimate) their swimwork or water processing rate by regulating the beat frequency (or power) of the cilia in response to the presence of a predator, or to a change in ambient water temperature (Riisgård \& Seerup 2003, Kittner \& Riisgård 2005, Riisgård \& Larsen 2007). Different coupling between metabolism $\left(Q_{10}\right)$ and propulsion mechanisms may explain why ciliary and muscular swimmers are not likely to be subject to identical changes in swimming velocity caused by changing temperatures. Thus, Beck \& Turingan (2007) observed that in the presence of a fish larval predator, copepods and brine shrimps are able to increase their swimming velocity 200 to $300 \%$, corresponding to $Q_{10}=2$ to 3 if the same effect was observed for a $10^{\circ} \mathrm{C}$ increase. This shows that these muscle-powered swimmers, in contrast to ciliary swimmers, possess a significant but usually not exploited potential for mobilizing supplementary swimpower. Mobilization of some of this extra swim-power may explain why some zooplankton organisms apparently manage to achieve the same swimming velocity with a temperature reduction as with additives, both giving the same increase in viscosity, and this despite an expected reduced metabolic rate for the temperature decrease. The above considerations, however, are not entirely supported by the results in the present study because the biological effect (fraction of total reduction of swimming velocity for a $10^{\circ} \mathrm{C}$ temperature reduction) was small or negligible for the copepod $(4 \%)$ but considerable for the brine shrimp (37\%) and the rotifer $(26 \%)$.

The many earlier reports on temperature effects on pumping, swimming and ingestion have left a confusing picture of the role of the physical/mechanical effect of viscosity, but the present study's experimental design and data treatment demonstrate how a biological effect may be separated from the physical/mechanical effect of changing temperatures. Still, it may also in future experiments be desirable to conduct direct measurements of the actual metabolic cost of swimming (or other activity) at different temperatures and different viscosities at constant temperature in order to separate the physical and biological effects of temperature.

Acknowledgements. H.U.R. was supported by a grant from the Danish Agency for Science and Technology and Innovation (grant no. 272-06-0478). The critical comments made by 3 anonymous reviewers significantly improved the present study.

\section{LITERATURE CITED}

Beck LJ, Turingan RG (2007) The effects of zooplankton swimming behavior on prey-capture kinematics of red drum larvae, Sciaenops ocellatus. Mar Biol 151:1463-1470 
Bolton TF, Havenhand JN (1997) Physiological versus viscosity-induced effects of water temperature on the swimming and sinking velocity of larvae of the serpulid polychaete Galeolaria caespitosa. Mar Ecol Prog Ser 159:209-218

Bolton TF, Havenhand JN (1998) Physiological versus viscosity-induced effects of an acute reduction in water temperature on microsphere ingestion by trochophore larvae of the serpulid polychaete Galeolaria caespitosa. J Plankton Res 20:2153-2164

Fuiman LA, Batty RS (1997) What a drag it is getting cold: partitioning the physical and physiological effects of temperature on fish swimming. J Exp Biol 200:1745-1755

Hunt von Herbing I, Keating K (2003) Temperature-induced changes in viscosity and its effects on swimming speed in larval haddock. In: Browman HI, Skiftesvik AB (eds) The big fish bang. Proc 26th Annu Larval Fish Conf 22-26th July 2002, Bergen. Institute of Marine Research, Bergen, p 23-34

Jakobsen HH, Everett LM, Strom SL (2006) Hydromechanical signaling between the ciliate Mesodinium pulex and motile prey. Aquat Microb Ecol 44:197-206

> Jiang H, Osborn TR (2004) Hydrodynamics of copepods: a review. Surv Geophys 25:339-370

Jonsson PR, Tiselius P (1990) Feeding behaviour, prey detection and capture efficiency of the copepod Acartia tonsa feeding on planktonic ciliates. Mar Ecol Prog Ser 60:35-44

Kiørboe T, Saiz E, Viitasalo M (1996) Prey switching behaviour in the planktonic copepod Acartia tonsa. Mar Ecol Prog Ser 143:65-75

Kittner C, Riisgård HU (2005) Effect of temperature on filtration rate in the mussel Mytilus edulis: no evidence for temperature compensation. Mar Ecol Prog Ser 305:147-152

Lagergren R, Lord H, Stenson JAE (2000) Influence of temperature on hydrodynamic costs of morphological defences

Editorial responsibility: Hidekatsu Yamazaki,

Tokyo, Japan in zooplankton: experiments on models of Eubosmina (Cladocera). Funct Ecol 14:380-387

Loiterton B, Sundbom M, Vrede T (2004) Separating physical and physiological effects of temperature on zooplankton feeding rate. Aquat Sci 66:123-129

Nielsen C (1987) Structure and function of metazoan ciliary bands and their phylogenetic significance. Acta Zool 68:205-262

Nielsen C (1995) Animal evolution. Interrelationships of the living phyla. Oxford University Press, Oxford

> Podolsky RD (1994) Temperature and water viscosity: physiological versus mechanical effects on suspension feeding. Science 265:100-103

Podolsky RD, Emlet RB (1993) Separating the effects of temperature and viscosity on swimming and water movement by sand dollar larvae (Dendraster excentricus). J Exp Biol 176:207-221

> Riisgård HU, Larsen PS (2007) Viscosity of seawater controls beat frequency of water-pumping cilia and filtration rate of mussels Mytilus edulis. Mar Ecol Prog Ser 343:141-150

Riisgård HU, Seerup DF (2003) Filtration rates in the soft clam Mya arenaria: effects of temperature and body size. Sarsia 88:415-428

Schmidt-Nielsen K (1970) Animal physiology. Prentice-Hall, Englewood Cliffs, NJ

Strathmann RR, Jahn TL, Fonseca JRC (1972) Suspension feeding by marine invertebrate larvae: clearance of particles by ciliated bands of a rotifer, pluteus, and trochophore. Biol Bull (Woods Hole) 142:505-519

Tiselius P, Jonsson PR (1990) Foraging behaviour of six calanoid copepods: observations and hydrodynamic analysis. Mar Ecol Prog Ser 66:23-33

White FM (2003) Fluid mechanics, 5th edn. McGraw-Hill, New York

Submitted: January 3, 2008; Accepted: August 25, 2008

Proofs received from author(s): October 7, 2008 